Cahiers $d u$ MONDE RUSSE

\section{Cahiers du monde russe}

Russie - Empire russe - Union soviétique et États indépendants

$46 / 4 \mid 2005$

L'invention d'une politique humanitaire

\title{
Adrienne Lynn Edgar, Tribal Nation
}

\section{Marco Buttino}

\section{OpenEdition}

Journals

Édition électronique

URL : https://journals.openedition.org/monderusse/6657

DOI : 10.4000/monderusse.6657

ISSN : $1777-5388$

Éditeur

Éditions de l'EHESS

Édition imprimée

Date de publication : 1 décembre 2005

Pagination : 962-966

ISBN : 2-7132-2057-2

ISSN : $1252-6576$

Référence électronique

Marco Buttino, « Adrienne Lynn Edgar, Tribal Nation », Cahiers du monde russe [En ligne], 46/4 | 2005, mis en ligne le 30 juin 2009, consulté le 03 septembre 2022. URL : http://journals.openedition.org/ monderusse/6657 ; DOI : https://doi.org/10.4000/monderusse.6657

Ce document a été généré automatiquement le 3 septembre 2022

Tous droits réservés 


\title{
Adrienne Lynn Edgar, Tribal Nation
}

\author{
Marco Buttino
}

\section{RÉFÉRENCE}

Adrienne Lynn EDGAR, Tribal Nation. The Making of Soviet Turkmenistan.

Princeton, Oxford : Princeton University Press, 2004, XVI-296 p.

1 Au milieu des années 1920, une fois l'Asie centrale reconquise par l'Armée rouge, les territoires du Turkestan, de l'émirat de Boukhara et du khanat de Khiva furent traversés par de nouvelles frontières. Naquirent ainsi les républiques soviétiques nationales fondées sur le principe de l'unité de territoire, de culture et de langue. Pendant longtemps, l'historiographie a considéré cette transformation comme le seul résultat de la politique imposée par Moscou du divide et impera visant à fragmenter des territoires dotés d'une unité politique, à diviser les élites politiques locales et à éradiquer les idéologies panislamique ou panturque jugées dangereuses. En réalité, la question est plus complexe : les décisions qui furent prises alors n'émanaient pas seulement de Moscou; elles visaient à créer de nouvelles élites locales, à les impliquer dans la construction du régime soviétique et à révolutionner les sociétés autochtones. La «politique des nationalités » était précisément l'instrument de ce projet.

2 Le livre d'Adrienne Lynn Edgar suit la voie ouverte par Terry Martin dans l'étude des politiques impériales soviétiques et se situe parmi les recherches récentes sur la construction nationale et sur la division des républiques d'Asie centrale (Francine Hirsch, Daniel Bower, Arne Haugen). A. L. Edgar affronte ces grandes questions en enquêtant en profondeur sur le cas d'une république, le Turkménistan. Le cas choisi est un excellent exemple pour mettre en évidence la complexité de la construction soviétique. Avant l'URSS, les Turkmènes étaient des peuples essentiellement nomades ou semi-nomades, qui habitaient des territoires immenses aux frontières toutefois imprécises, qui parlaient des langues différentes et se reconnaissaient pour la plupart dans des tribus fondées sur des généalogies imaginaires. Comment a-t-il été possible qu'en quelques années se soit construite une nation turkmène? Cette édification, comme l'explique l'auteur, fut en 
réalité le résultat d'un compromis entre plusieurs exigences, une construction ambiguë qui ne demeura dans une certaine mesure qu'une apparence.

3 La politique soviétique des nationalités ne laissait pas de place à des appartenances multiples et fluctuantes, elle exigeait de ramener à l'unité une société divisée et de construire des formes d'appartenance univoques. Chercheurs et experts se mobilisèrent ainsi pour distinguer, cataloguer, puis unifier les différentes composantes de cette société. Des documents du Bureau politique d'Asie centrale (Sredazbjuro CK VKP) examinés par A.L. Edgar affleurent les conflits sur l'attribution nationale des groupes tribaux et la ferme volonté de déterminer des appartenances présumées réelles, même si elles n'étaient souvent pas reconnues par les intéressés. Ces choix, qui conduisaient à des regroupements et à des divisions entre populations, étaient évidemment politiques et avaient comme protagonistes d'une part Moscou, mais d'autre part aussi les divers pouvoirs internes de la société locale et les représentants des nombreux groupes tribaux avec leurs stratégies particulières. La division de l'Asie centrale en républiques nationales en 1924-1925 fut le résultat de ce processus complexe.

Dans l'intention des Soviétiques, la nouvelle division territoriale devait être légitimée par la création d'institutions politiques et administratives nationales, celles-ci reposant sur la korenizacija (c'est-à-dire qu'elles devaient trouver leurs racines dans la population locale). Les Turkmènes participèrent ainsi à toutes les nouvelles instances du pays et leur langue fut adoptée partout. Leur implication, qui naturellement ne devait pas miner l'ordre établi par Moscou et valable pour toutes les républiques, déclencha toutefois des conflits, soit entre les nombreuses factions tribales rivalisant pour obtenir des postes importants dans le nouvel État, soit avec les Russes locaux. Ces derniers, qui avaient un rôle dominant et une attitude de colonisateurs, résistèrent quand on leur demanda de partager le pouvoir avec les autochtones. Ils soutinrent que ceux-ci n'avaient pas un niveau d'instruction suffisant pour assumer des fonctions de responsabilité et que les rares gens instruits appartenaient aux classes auparavant dominantes et étaient donc peu fiables. Les résistances à la korenizacija se poursuivirent après la fin des années 1920 quand le démarrage du premier plan quinquennal augmenta le besoin en cadres locaux. Des compromis s'avérèrent nécessaires, mais ils furent ensuite continuellement remis en cause par les campagnes d'épuration lancées par Moscou et appuyées sur place par des relais actifs. L'intelligentsia autochtone fut balayée par les épurations entre la fin des années 1920 et le début des années 1930, puis par la grande répression des années de terreur.

La participation des Turkmènes et l'adoption de leur langue dans les institutions soviétiques impliquaient que l'on puisse se référer à une « nationalité » turkmène - il en a déjà été question - mais aussi à une langue turkmène. Ce dernier problème n'était pas facile à résoudre. L'un des aspects concernait le choix des caractères pour la transcription: on adopta d'abord les caractères latins pour opter finalement, en 1940, pour l'alphabet cyrillique. Un autre aspect, plus complexe, concernait la création d'une langue turkmène unique, alors que les tribus parlaient des langues différentes, même si elles se comprenaient entre elles. Dans les années 1920, les intellectuels locaux travaillèrent à l'établissement d'une langue écrite intermédiaire entre les langues parlées. Moscou encourageait cette démarche qui, appliquée à toutes les républiques d'Asie centrale, menait à distinguer et à accentuer les écarts entre les différentes langues nationales officielles. Cette approche s'opposait à la recherche d'une langue commune qui avait été soutenue par les tendances panturques du mouvement des djadids. Plus 
tard, dans les années 1930, on décida à Moscou que la construction linguistique opérée par les intellectuels autochtones devait être corrigée, épurée de toute intention nationaliste, de façon à offrir une place moins aux langues parlées, considérées comme tribales, qu'à celle des «secteurs progressistes» de la société. L'idéologie plaçait au centre de l'attention les ouvriers et donc les villes. Ce choix fut renforcé quand on décida que les emprunts à d'autres langues devaient provenir principalement du russe. Ainsi Moscou modifia les choix linguistiques, épura la communauté des linguistes et les politiciens locaux, enfin dicta le choix des caractères cyrilliques.

6 Malgré la division de l'Asie centrale en républiques nationales, l'imposition du système soviétique et de sa politique linguistique, la révolution ne parvint pas à entamer la société turkmène et à la transformer en profondeur. On était en présence d'un État soviétique fondé sur une rhétorique de classe face à une société qui fonctionnait sur la base de loyautés et d'inimitiés tribales. Jusque dans les années 1930, les initiatives soviétiques n'aboutirent qu'à l'effet inverse du but recherché. Elles visaient l'abolition des appartenances tribales et claniques, mais ne firent que les renforcer. Il en fut ainsi par exemple de la réforme agraire de la seconde moitié des années 1920. La redistribution des droits à la terre et à l'eau devait avantager les couches défavorisées de la population. Mais dans la société turkmène, les différences de pouvoir et de richesse reposaient sur les appartenances tribales : la redistribution tentée par la réforme suscita donc des conflits entre tribus et consolida ainsi ce qu'elle voulait éliminer. En outre, il s'avérait que les groupes les plus puissants avaient davantage d'influence dans les soviets locaux et qu'ils pouvaient tourner à leur profit les choix qui, officiellement, avaient été faits au détriment des couches aisées de la population. Par conséquent, il arrivait souvent que des membres des groupes les plus faibles, exclus des soviets locaux, soient traités comme s'ils appartenaient à la classe des exploiteurs. La rhétorique élaborée par les dirigeants politiques communistes résidant à des milliers de kilomètres se traduisait par une pratique qui produisait des résultats opposés.

7 La grande offensive contre la société turkmène eut lieu avec la collectivisation. Celle-ci provoqua la destruction de la société nomade et paysanne. L'étude de A. L. Edgar s'arrête au début des années 1930 sans pénétrer plus avant dans le terrain complexe de la collectivisation, ce qui aurait demandé un travail dépassant le cadre de ce livre. Ce qui se passa au Turkménistan fut probablement assez semblable à ce qui se produisit dans les steppes du Kazakhstan et dans les montagnes du Kirghizstan (voir les travaux d'Isabelle Ohayon et de Niccolò Pianciola). A. L. Edgar décrit toutefois de manière exhaustive les premiers effets de la collectivisation : la famine et l'émigration massive de réfugiés. Au Turkménistan, comme en Ouzbékistan, la collectivisation entraîna les campagnes vers la monoculture du coton et renforça la dépendance à l'égard de la Russie.

Moscou voulait aussi combattre les cultures locales de façon à ouvrir la voie à la création d'une nouvelle culture commune, soviétique. Ainsi, entre les années 1920 et le début des années 1930, fut menée dans toute l'Asie centrale une campagne qui avait pour objectif de faire changer profondément les modes de vie locaux. Observer les traditions devint un délit. A. L. Edgar analyse avec soin les divers aspects de cette politique : abolition par décret du galing (prix de la fiancée), de la polygamie, du mariage en bas âge et d'autres coutumes. Cette étude est très intéressante parce qu'elle enquête sur la signification de ces institutions turkmènes et montre combien les communistes européens se sont mépris sur leur compte. Les conventions qui réglaient les relations sociales (il ne s'agissait pas de coutumes éphémères) furent remises en cause sans que l'on en 
comprenne la complexité et la subtilité. Une mentalité coloniale, jointe à l'illusion de la modernisation, était à l'origine de ces mesures qui provoquèrent des dégâts sans produire les changements voulus. L'interdiction de l'observance des traditions dans le proche Ouzbékistan se concentra sur l'hujum, le port du voile, et se heurta aux mêmes résistances, avec les mêmes résultats (comme le montrent les études de Douglas Northrop). Les femmes turkmènes ne portaient pas le voile en tant que symbole visible de soumission, mais elles étaient tout aussi opprimées et on essaya de les émanciper à force de décrets. Les Soviétiques voulaient provoquer une révolution culturelle, mais la société turkmène se défendit, aussi longtemps que cela fut possible, en déjouant les contrôles et en dissimulant l'observance des traditions sous une apparence soviétique.

9 Sur plusieurs points, le texte de A. L. Edgar se réfère à juste titre à des études sur les régimes coloniaux d'autres pays. En effet, création d'un territoire national et d'institutions administratives locales, standardisation de la langue, construction d'un système d'éducation de masse et méfiance envers les cultures locales sont des aspects caractéristiques des politiques coloniales, et on les retrouve en URSS - en particulier dans l'Asie centrale soviétique. Un objectif analogue de modernisation et de civilisation inspira la politique anglaise ou française dans les colonies, et il en fut de même pour la politique russe dans la périphérie asiatique. Au-delà des différences, on découvre des éléments communs aux diverses expériences coloniales, et aussi une continuité entre l'époque tsariste et soviétique. Toutefois, selon l'auteur, il y aurait une différence: l'Union soviétique n'a jamais fondé sa politique sur le concept d'une supériorité de race, jamais institutionnalisé la primauté des Russes et toujours affirmé l'égalité entre ses citoyens. Les violences contre la périphérie ne furent d'ailleurs pas différentes de celles que la Russie mit en œuvre chez elle. L'URSS fut donc un empire comparable aux autres, avec cependant des particularités, et elle tenta à sa façon d'européaniser les peuples sous sa domination.

Le livre de A. L. Edgar nous aide à comprendre la situation actuelle du Turkménistan et celle des autres républiques d'Asie centrale. Un héritage soviétique existe, que l'on ne doit pas négliger, mais il y a aussi des éléments semblables à la situation d'autres pays d'Asie ou d'Afrique sortis d'une expérience coloniale : difficultés économiques, crise des institutions de l'État, nouvelle écriture de l'histoire et volonté de retourner à un passé mythique précolonial, débats sur les frontières et sur les langues, culture partagée entre retour aux traditions et fascination de l'Occident, relations importantes mais difficiles avec l'ancienne métropole coloniale. Cette étude de cas approfondie sur le Turkménistan éclaire un contexte particulier et incite à d'autres recherches comparatives. 